\title{
Fatigue reliability analysis of running system of large passenger vehicle considering velocity distribution
}

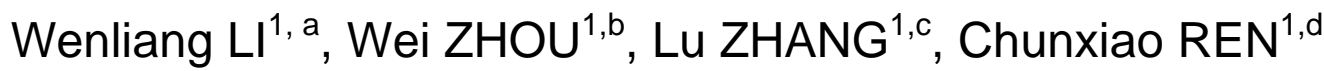 \\ ${ }^{1}$ Research Institute of Highway Ministry of Transport, Beijing 100088, China \\ awl.li@rioh.cn, bw.zhou@rioh.cn, ${ }^{\mathrm{c}} 443933501 @ q q . c o m,{ }^{\mathrm{d}} \mathrm{cx} . r e n @$ rioh.cn
}

Keywords: large passenger vehicle; velocity distribution; running system; fatigue;

\begin{abstract}
Based on the theory of nominal damage prediction, the influence of vehicle velocity on fatigue damage is analyzed, and the equivalent coefficient of different speed is proposed. The real vehicle test is carried out, and the equivalent coefficient of different velocity is calculated, and the fatigue reliability of running system is analyzed.
\end{abstract}

\section{Introduction}

Reliability is the basic guarantee for the safe operation of vehicles, and also the necessary condition for ensuring the transportation efficiency. From 1970s, the domestic and foreign scholars have carried out a lot of research on the fatigue life prediction of automobile and parts. In 2012, KUEH J J[1] analyzed the static fatigue of composite steel plate spring with the same size, and obtained the influence of the composition of the steel plate spring on the deflection and fatigue life; Kolokol'tsev V A[2] used the spectral analysis method based on statistical dynamics to calculate the strength and fatigue life of the vehicle support system under the condition of random vibration; Mironov V I[3] established a periodic degradation model of vehicle parts materials; In 2012, the corrosion fatigue of welded aluminum vehicle structure under constant amplitude and variable amplitude cyclic loading was studied by Sonsino C M[4]; In 2013, the fatigue of solder joints under the actual operating conditions was studied by Miki C[5]; In 2014, Zhao L H[6] estimated the fatigue life of vehicle rear axle considering the role of below the fatigue limit operation load on fatigue damage. In China, Yuanzhang Sun[7] put forward the evaluation index system of power system operation reliability in 2005; in 2011, Ding Feng[8]established the relationship between the tool vibration state information and the tool wear life; Baojia Chen[9]used the tool vibration signal accurately to estimate the reliability of the cutting tool.

The large operating passenger vehicle has the characteristics of large capacity, long distance, and so on. Fatigue failure of driving system may burst under loading and road complex loading, which would cause fatal road traffic accidents [10]. Therefore, this paper mainly analyzes the influence of driving speed on the fatigue reliability of large operating passenger vehicle.

\section{Theory analysis}

\section{Pseudo Damage}

In the practical reliability engineering practice, the stress, strain, acceleration, displacement, torque, force, etc. from the angle of energy, can be called the generalized stress ". Taking the "generalized stress" as the input, using the rain flow counting method to calculate the load cycle number; according to the S-N curve and the Miner rule, the damage is called nominal damage or pseudo damage[11].

$$
N=N_{0}\left(S / S_{0}\right)^{1 / b} \text {. }
$$

Where $N$ is the number of failure cycles, and $S_{0}$ is the fatigue limit, and $S$ is the alternating stress, and $b$ is the Basquin slope. 


\section{Palmgren-Miner Linear cumulative damage rule}

Miner assumed that when the absorbing energy reaches limit, fatigue failure happens; the absorbing energy is proportional to number of cycles. $W$ is absorbing energy limit value before the failure; $N$ is the number of total cycles before the failure; When the number of cycles is $n_{1}$, correspondingly the absorbing energy is $W_{1}$, there are

$$
\frac{W_{1}}{W}=\frac{n_{1}}{N}
$$

If a specimen loading history is organized by different stress levels as $\sigma_{1}, \sigma_{2}, \cdots, \sigma_{l}$, correspondingly number of cycles is $n_{1}, n_{2}, \cdots, n_{l}$, then damage value of Miner rule can be expressed as,

$$
D=\sum_{i=1}^{l} n_{i} / N_{i}
$$

When $D$ is 1 , absorbing energy reaches the limit value, and fatigue failure happens.

\section{Equivalent coefficient of different velocity section}

The speed is divided into 5 segments, and the mileage proportion is present with $p_{i} \quad(\mathrm{i}=1,2,3,4,5)$, as shown in Table 1.

Table 1 velocity section

\begin{tabular}{ccc}
\hline symbol & meaning & unit \\
\hline$p_{1}$ & mileage proportion of $0 \sim 30 \mathrm{~km} / \mathrm{h}$ & $\%$ \\
$p_{2}$ & mileage proportion of $30 \sim 50 \mathrm{~km} / \mathrm{h}$ & $\%$ \\
$p_{3}$ & mileage proportion of $50 \sim 70 \mathrm{~km} / \mathrm{h}$ & $\%$ \\
$p_{4}$ & mileage proportion of $70 \sim 90 \mathrm{~km} / \mathrm{h}$ & $\%$ \\
$p_{5}$ & mileage proportion of $90 \sim$ & $\%$ \\
\hline
\end{tabular}

The equivalent coefficient reflects the equivalent relationship between the nominal fatigue damage caused by the load of the different speeds under the same driving range. The nominal damage is used as the basis of the fatigue load caused by the speed of $0 \sim 30 \mathrm{~km} / \mathrm{h}$, and the equivalent load of the corresponding load is calculated.

$$
K_{i}=\frac{D_{i}}{D_{1}}
$$

Where $D_{i}(i=1,2,3,4,5)$ are respectively the nominal damage of fatigue load of unit mileage under $0 \sim 30 \mathrm{~km} / \mathrm{h} 、 30 \sim 50 \mathrm{~km} / \mathrm{h} 、 50 \sim 70 \mathrm{~km} / \mathrm{h} 、 70 \sim 90 \mathrm{~km} / \mathrm{h} 、 90 \sim$.

\section{Real vehicle test}

Vehicle is fully loaded, pavement is dry. Z direction vibration and GPS signal are collected with eDAQ test platform, as shown in Fig.1.

Glyphworks software is used to calculate the nominal damage of the vehicle driving system, as shown in Fig.2, which mainly includes two modules: the burr and the damage calculation.

Burr is detected using automatic gradient method (AutoDifferential). The slope of SN is -3, and the intercept is 150 .

Damage caused by the fatigue load of each velocity section is calculated with Eq. 1- Eq. 3, and equivalent coefficients are calculated with Eq. 4, as shown in table 2. 

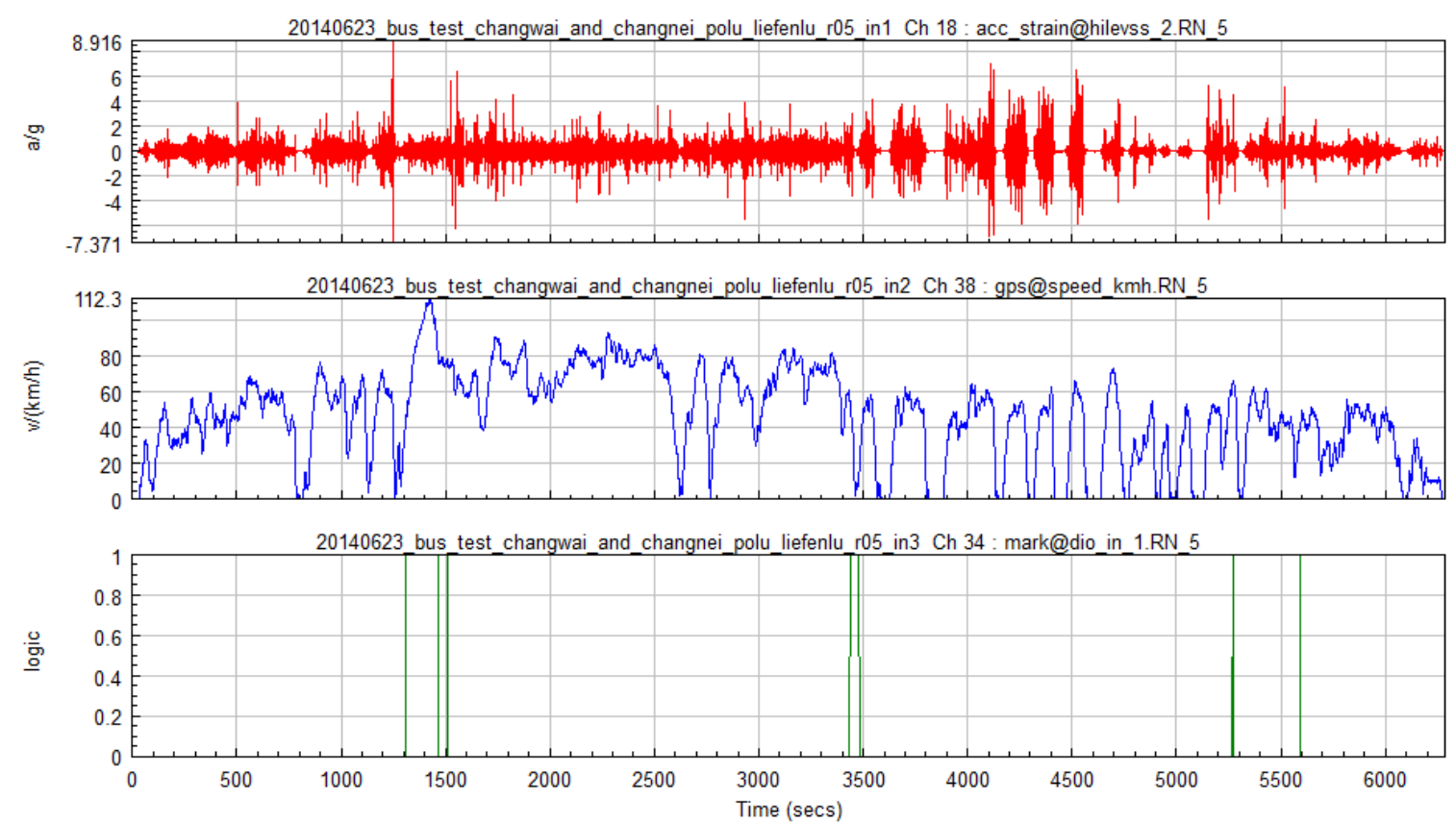

Fig.1 Z direction vibration signal of spindle and GPS speed signal



Fig.2 Nominal damage calculation process

Table 2 The equivalent coefficient

\begin{tabular}{ccccc}
\hline $\begin{array}{c}\text { velocity section } \\
(\mathrm{km} / \mathrm{h})\end{array}$ & Mileage /m & Nominal damage & $\begin{array}{c}\text { Nominal damage per } \\
\text { mileage }\end{array}$ & $\begin{array}{c}\text { equivalent } \\
\text { coefficient }\end{array}$ \\
\hline $0-30$ & $4.462 \mathrm{e}+003$ & $4.04012 \mathrm{e}-004$ & $9.05450 \mathrm{E}-08$ & 1.00 \\
$30-50$ & $1.925 \mathrm{e}+004$ & $1.3379 \mathrm{e}-002$ & $95013 \mathrm{E}-07$ & 7.68 \\
$50-70$ & $2.981 \mathrm{e}+004$ & $2.65969 \mathrm{e}-002$ & $8.92214 \mathrm{E}-07$ & 9.85 \\
$70-90$ & $2.43 \mathrm{e}+004$ & $7.5042 \mathrm{e}-003$ & $3.08815 \mathrm{E}-07$ & 3.41 \\
$90-$ & $2.7911 \mathrm{e}+003$ & $1.12493 \mathrm{e}-003$ & $4.03042 \mathrm{E}-07$ & 4.45 \\
\hline
\end{tabular}

We can see from Table 2 that, the equivalent coefficient first increases and then decreases with the increase of the speed, and reaches the peak value at $50-70 \mathrm{~km} / \mathrm{h}$ velocity.

Vehicle speed distribution is different with different operating lines. For the same reliability design target, the actual service life is longer with larger mileage proportion of $0 \sim 30 \mathrm{~km} / \mathrm{h}$ and 
shorter with larger mileage proportion of $50 \sim 70 \mathrm{~km} / \mathrm{h}$. The theoretical maximum and minimum values of actual service life can vary between $8 \sim 9$ times.

\section{Summary}

Taking the large working bus as the research object, based on the theory of nominal damage prediction, the influence of the vehicle traveling speed on the fatigue damage of driving system is analyzed, and the equivalent coefficient of the vehicle is studied. The results show that the equivalent coefficient increases first and then decreases with the increase of the speed of the vehicle, and the peak value is reached at the speed of $50-70 \mathrm{~km} / \mathrm{h}$. Vehicle speed distribution is different with different operating lines. For the same reliability design target, the actual service life is longer with larger mileage proportion of $0 \sim 30 \mathrm{~km} / \mathrm{h}$ and shorter with larger mileage proportion of $50 \sim 70 \mathrm{~km} / \mathrm{h}$. The theoretical maximum and minimum values of actual service life can vary between $8 \sim 9$ times, and the difference is very obvious. Speed of $50 \sim 70 \mathrm{~km} / \mathrm{h}$ should be avoided considering vehicle reliability.

\section{References}

[1] KUEH J J, FARIS T. Finite Element Analysis on the Static and Fatigue Characteristics of Composite Multi-Leaf Spring [J]. Journal of Zhejiang University-SCIENCE A (Applied Physics \& Engineering), 2012, 13(3):159-164.

[2] Kolokol' tsev V A, Avramov M V. Fatigue Life of Vehicle Vomponents[J].Russian Engineering Research,2012,32(9-10):636-640.

[3] Mironov V I, Lukashuk O A, Yakushev A V, et al. Cyclic Degradation of Material in Vehicle Components[J].Russian Engineering Research,2012,32(5-6):417-422.

[4] Sonsino C M, Morgenstern C, Streicher M,et al.Corrosion Fatigue Of Welded Aluminium Vehicle Structures Under Constant And Variable Amplitude Loadings[J]. Welding in the World,2012,56(7-8):97-108.

[5] Miki C, Tai M.Fatigue Strength Improvement of out-of-Plane Welded Joints of Steel Girder under Variable Amplitude Loading[J].Welding in the World, 2013,57(6): 823-840.

[6] Zhao L H,Zheng S L,Feng J Z,et al.Fatigue Assessment of Rear Axle under Service Loading Histories Considering the Strengthening and Damaging Effects of Loads below Fatigue Limit[J].International Journal of Automotive Technology,2014,15(5): 843-852.

[7] Sun Yuanzhang, Cheng Lin, Liu Haitao, et al. Power system operational reliability evaluation based on real time operating state. Proceedings of 7th International Power Engineering Conference (IPEC2005)[C].New Jersey: IEEE Computer Society,2005: 722- 727.

[8] Ding Feng,He Jiazheng. Cutting Tool Wear Monitoring for Reliability Analysis Using Proportional Hazards Model[J]. International Journal of Advanced Manufacturing Technology,2011,57(5-8):565-574.

[9] Chen Baojia,Chen Xuefeng,Li Bing,et al. Reliability Estimation for Cutting Tools based on Logistic Regression Model Using Vibration Signals[J]. Mechanical Systems and Signal Processing,2011,25(7):2526-2537.

[10] Stevenson M E, McDougall J L,Vernon E E , et al. Failure Analysis in a Vehicle Accident Reconstruction[J].Journal of Failure Analysis and Prevention,2004,4(2):49-55.

[11]Wang Wan-ying, Wu Shun-hong, Tang Bei-ping, et al. Study on Equivalent Relation of Proving Ground and Real Road[J]. Journal of Chongqing University of Technology(Natural Science), 2010,24(12):15-19. 